\title{
J(e)
}

\begin{tabular}{|l||c|c|}
\hline \hline Received 22.12.2020 & & JOTS \\
$5 / 1$ \\
\hline \hline Accepted 06.01.2021 & Review & $2021: 240-246$ \\
\hline \hline Published 10.01.2021 & & \\
\hline
\end{tabular}

\section{Uzunkaya, U. Budist Eski Uygur Edebiyatından İki Metin, İstanbul: Kesit Yayınlar1, 2020, ss. 300, ISBN: 978-6057- 898890}

\author{
Hüseyin YILdiz \\ Ordu University (Ordu/Turkey) \\ E-mail: huseyinyildiz@odu.edu.tr
}

Yüksek lisansını Sakarya üniversitesinde XVI. yüzyılın sonuna ait Felāhatnāme adlı metin neşriyle Doç. Dr. P. Küçüker danışmalığında tamamlayan U. Uzunkaya, doktor unvanını Yıldız Teknik üniversitesinde Prof. Dr. M. Ölmez danışmanlığında hazırlandığı Son Dönem Budist Uygur Edebiyatından İki Örnek başlıklı teziyle 2017 yılında almıştır. T. Karaayak ve M. Ölmez'le birlikte kaleme aldığı telif ve çeviri yazılarının yanı sıra, tek isimli yayınladığı çalışmaları da bulunan Uzunkaya, Eski Türkçe alanına yoğunlaşmış görünse de Eski Oğuz Türkçesine yönelik çalışmalar da kaleme almaktadır.

Uzunkaya'nın bu yazının başlığında yer alan eseri, 2020 yılının son çeyreğinde neşredilmiş olup, aynı zamanda yazarın doktora tezinin düzenlenmiş hâlidir. Bahse konu metin, yazarın da Ön Söz'de belirttiği üzere Türkische Turfan Texte $V^{\prime}$ in başka fragmanlar eklenerek yapılan yeniden neşridir.

Kaynakça hariç yedi bölümden oluşan eserin ilk bölümü Giriş başlığını taşımaktadır (s. 19-33). Bu bölümde çalışmada yer alan yazmalar tanıtılmış, bu yazmalar üzerine yapılan çalışmalardan bahsedilmiş, çalışmanın yöntemi açıklanmış ve yazmaların biçim ve içerik özellikleriyle Çince eş değer metinlerine değinilmiştir.

ORCID ID: 0000-0002-8055-7946. 


\section{ग(৫)}

İkinci bölüm Tibet Budizmi başlığını taşımakta olup (s. 35-84), esasında Giriş bölümü içinde ele alınabilirdi. Nitekim çalışmanın diğer bölümleri olan Metin, Çeviri, Açılkamalar ve Dizinler başlıklarıyla kıyaslandığında, çalışmanın adının da metin neşrine hitap ettiği hatırlandığında bu tarz bir tasarruf isabetli olabilirdi. Ancak, gerek neşredilen metinlerin içerikleri, gerekse Tibet Budizmi için verilerin bilgilerin hacmi, yazarın bu kısmı ayrı bir bölüm olarak değerlendirmesine sebep olmuş olmalıdır. Bu bölümdeki bilgileri yazar, içinde farklı başlıklar da bulunan üç alt başlıkta sunmuştur. İlk alt başlıkta Budizm ve Tibet Budizmi'ne kadar bilinen Budist ekoller konusunu ele almış; Buddha, Budizm, Theravāda Budizmi, Mahāyāna Budizmi, Tantra Budizmi ve Vajrayāna hakkında bilgiler verilmiştir. İkinci alt başlıkta Tibet Budizmi tarihî arka plan, öğreti, mezhepler ve terminoloji bakımından ele alınmakta; üçüncü alt başlıkta ise Eski Uygurca Tibet Budizmi'ne ilişkin metinler, her birine dair bir iki paragraflık bilgiler verilmek suretiyle 24 başlıkta şu şekilde listelenmektedir:

Amṛtadundubhisvaradhāraṇī

Ārya-aparimitāyur-jñāna-nāma-mahāyāna-sūtra

Ārya-rājāvavādaka-sūtra

Ārya-sarva-durgati-pariśodhana-uṣnịṣavijayā-nāma-dhāraṇī

Ārya-sarva-tathāgata-uṣnị̣̄a-sitātapatrā-nāma-aparājitā-dhāraṇi

Avalokiteśvara-sādhana

Bahşı Ögdisi

Beş Dhyāni Buddha'nın Tasvirinden

Cakrasaṃvara'ya İlişkin Üç Metin

Eski Uygurca Bar do thos grol ve Buna İlişkin Diğer Eserler

Kāyacakra-sādhana

Mañjuśrī-nāma-saṃgīti

Mañjuśrīsadhana

Pañcaraḳsā

Sa-skya Paṇdita'nın Guruyogası

Saharākṣa-sahasrabāhv-avalokiteśvarabodhisattva-dhāraṇyṛddhhi-mantra-sūtra

Śrīcakrasaṃvaramaṇḍalābhisamaya 


\section{J(৫)}

Tārā-ekaviṃśati-stotra

Tejo-Mahākāla'nın Tasviri

Vajrapāṇi Metni

Vajrapāni-sādhana

Vajrasattva-mantra'nın İki Fragmanı

Vajravidāraṇā-nāma-dhāraṇīsadhana

Tibet Budizmine Ait Diğer Fragmanlar

Çalışmanın üçüncü bölümü Metin başlığını taşımakta olup (s. 85-132), sırasıyla $A, B^{1}, B^{2}, B^{3}, B^{4}$ metinlerinin çeviri yazısı ve harf çevirileri verilmektedir. Toplam 453 satırdan oluşan metinlerin bilgileri tarafımızdan hazırlanan şu tabloyla gösterilebilir:

\begin{tabular}{|c|c|c|c|}
\hline Metin Ad 1 & Numarası & Satır No & Satır Sayısı \\
\hline A & Mainz 732 (T II Y 21) & $001-150$ & 150 \\
\hline $\mathrm{B}^{1}$ & Mainz 732 (T II Y 21) [Taishō 1723, c. 34] & $151-280$ & 129 \\
\hline $\mathrm{B}^{2}$ & Hedin Ms. Nr. 41 (T II Y 21) [Taishō 1723, c. 34] & $281-296$ & 16 (ön 8 , arka 8) \\
\hline \multirow{7}{*}{$\mathrm{B}^{3}$} & \multirow{7}{*}{$\begin{array}{l}\text { Musée Guimet, Manuscrit Ouigour Nr. } 63322 \\
\text { A G (T II Y 21) [Taishō 1723, c. 34] }\end{array}$} & $297-312$ & $A=16$ (ön $8, \operatorname{arka~8)}$ \\
\hline & & $313-328$ & $\mathrm{~B}=16($ ön $8, \operatorname{arka} 8)$ \\
\hline & & $329-344$ & $C=16($ ön $8, \operatorname{arka} 8)$ \\
\hline & & $345-360$ & $\mathrm{D}=16($ ön $8, \operatorname{arka} 8)$ \\
\hline & & $361-376$ & $E=16($ ön $8, \operatorname{arka~} 8)$ \\
\hline & & $377-392$ & $\mathrm{~F}=16($ ön $8, \operatorname{arka} 8)$ \\
\hline & & 393-395 & $G=3$ \\
\hline \multirow{3}{*}{$\mathrm{B}^{4}$} & Haneda Nr. 61 (T II Y 21) [Taishō 1723, c. 34] & $396-411$ & 16 (ön 8 , arka 8) \\
\hline & Haneda Nr. 73 (T II Y 21) [Taishō 1723, c. 34] & $412-427$ & 16 (ön 8, arka 8) \\
\hline & Haneda Nr. 34 (T II Y 21) [Taishō 1723, c. 34] & $428-453$ & 26 (ön 13, arka 23) \\
\hline
\end{tabular}

Tabloda yer alan metinlerin Türkiye Türkçesine çevirileri aynı sırayla dördüncü bölümde (s. 133-142) verilmiştir.

Neşir sisteminde üst satır transkripsiyon (yazı çevrimi), alt satır küçük harfli transliterasyon (harf çevrimi) yöntemini kullanan Uzunkaya, B yazmalarının okunuşunda üçüncü bir satır ekleyerek yer yer Çince biçimleri de göstermiştir. Metin okuması genel olarak başarılı olmakla beraber Uzunkaya'nın gözünden kaçan birkaç hususa burada yer vermek iyi olacaktır. 
İlk olarak A metninde ikinci satırda gösterilen ... [y]aşuk alku-ibaresi ... ... ... [yaruk] [y]aşuk alku-] şeklinde de tamamlanabilirdi. Nitekim ilerleyen satırlarda şu ifadeleri görüyoruz:

005-007 ... ay $\mathrm{t}($ ä)yri ordosı täg yaruk yaşuk alkudın sı̀ar yarumışın yaşumışın sakınmış k(ä)rgäk...

007-010 ... bel yokaru köküz äginkä tägi ot ulug tetir ot öylüg yaruk yaşuk alkudın sıjar yaltr(1)mışın yaşumışın sakınmış k(ä)rgäk...

012-014 ... yürün yipin öylüg yaruk yaşuk alkudın sı̀ar yarumışın yaşumışın sakınmış k(ä)rgäk...

Ayrıca 27. satırda yer alan t(ä)ngri kelimesi metinde geçtiği diğer 25 yerde (örn. 145. Satır) t(ä)yri şeklinde yazılmıştır. Harf çevrimleri aynı olan bu kelimenin yazımında 27. satırdaki kelime gözden kaçmış olmalıdır.

Kitabın beşinci bölümü Açılamalar'a ayrılmıştır (s. 143-202). Çoğu, çalışmada yer alan metinlerde geçen sözlere ait notları içeren bu açıklamalar Uyguristik sahası metin neşirlerinde önem arz etmektedir. Esasında bu tür notlara ilişkin bir dizinin de çalışmalarda yer alması isabetli olurdu, ancak pek çok çalışmada olduğu gibi bu çalışmada da bir notlar dizini yer almamıştır. Bununla beraber çoğu çeşitli kelime, tamlama ve sözlere ait olan 431 not çalışmanın anlaşılmasında önemli ipuçları sunmaktadır. Notların genelinde iki yöntem kullanıldığı anlaşılmaktadır. İlk yöntemde not düşülen kelimeden sonra iki nokta üst üste kullanılarak açıklama yapılmakta; ikinci yönteme göre ise not düşülen kelimenin önce anlamı tırnak içinde verilmekte ardından açıklaması ayrı cümlede yer almaktadır. Her iki yönteme göre ikişer örnek vermek yeterli olacaktır.

İlk yönteme göre:

049 tuymak bilig: Burada tuymak bilig, Skr. bodhi karşllı̆̆nda kullanılmıştır. Skr. 'bilinçli, anlayışlı' anlamındaki bodha sözcügünden gelen bodhi 'aydınlanma' anlamındadır (Soothill, Hodous, 1937, 480a). Sözcük ayrıca 'kusursuz bilgi ve bilgelik' anlamlarına da gelir (Monier-Williams, 1899, 734c).

151 kägdä: Soğdcada $k^{\prime} \gamma \delta^{\prime} \sim k^{\prime} \gamma \delta^{\prime} k h$ yazımına sahip sözcük 'kağıt' anlamındadır (Gharib, 1995, 185b, 4632. ve 4634. madde başı). Bodrogligeti'ye göre, Soğdca kökenli bu sözcük Manihaist kanallar vasıtasıyla Uygurlar tarafindan ödünçlenmiştir (Bodrogligeti, 1965, 107).

İkinci yönteme göre: 
026 ontun sıyarkı burhanlar 'on taraftaki Buddhalar'. 'On yön' anlamındaki bu terimle kâinat kast edilmektedir (Soothill, Hodous, 1937, 426a). Kâinat, uzayın on yönü veya başka bir deyişle pusulanın sekiz yönü (kuzey, güney, doğu, batı, kuzeydoğu, kuzeybatı, güneydoğu ve güneybatı) ve en üst nokta ile en alt noktadan toplamda on yönden oluşur. Her bir yön için bir Buddha vardır (Soothill, Hodous, 1937, 50b).

064 biliglär ‘semboller, belirtiler'. Bang ve Gabain bilig sözcüğünün burada 'belirti, işaret, özellik, nitelik, sembol' gibi bir anlama gelmesi gerektiğini belirtmiştir (Bang, Gabain, 1931b, 337, 64. n.). Krş. 092. satır.

Açıklamalarda iki yerde yazım yanlışı yapılmıştır. 118. notta ilk satırda, 123. notta ise 6. satırda daya(na)rak kelimesi bir hece eksik yazılmıştır.

Çalışmanın Dizin bölümü (s. 203-279) üçe ayrılmıştır: 1. Uygurca Dizin, 2. Çince - Uygurca Dizin, 3. İkilemeler Dizini. Uygurca Dizin, kısmında genel olarak bir düzen görülmekle birlikte yer yer sıralama hatalarıyla karşılaşılmaktadır. Sözgelimi dizinin ilk sayfasındaki (s. 203) kelime sırası şu şekildedir:

a, aç-, ada, adaksız, adın, Adaş Kaya, adak, adaklıg, adınçıg, adıra, adırt.

$\mathrm{Bu}$ sıralamaya göre adaksız kelimesi adak ve adaklıg kelimelerinden; adın kelimesi ise Adaş Kaya, adak, adaklıg kelimelerinden önce gelmektedirler. Dizgi hatası olması kuvvetle muhtemel olan bu durumun kontrol edilmesi ve baskı öncesi düzeltilmesi icap ederdi. Doğru sıralamanın şu şekilde olması gerekirdi:

a, aç-, ada, adak, adaklıg, adaksız, Adaş Kaya, adın, adınçıg, adıra, adırt.

Benzer durumlara sonraki sayfalarda da rastlanmaktadır:

s. $204 \rightarrow$ adirtla-, adkan-, adkangu, adro-, adromak, adrok, agulug, akıl-, al, adırtlamak, adırtmak, ag(1)r, agır, ag(1)rla-, agırla-, al-, alın-, alk-.

s. $205 \rightarrow$ alkın-, alku, alkudın, alyad-, alyad̦turur-, alyadtur-, alp, alkış, altag, altı, altın, altınç, altun, amırtgur-, amitabaya, amrıl-, amrıltur-.

s. 242-243 $\rightarrow$ säkizinç, s(ä)n, säv-, sävin-, sävinç, sävitmäk, sezik, seziklig, seziksiz, sezin-, smarta, sola-, söz, sözlä-, sözlämäk, sözlämäklig, sık-, sı๖ar, sınça, sırıçga, sidị, sim, sudur.

Çalışmanın tez haline bakıldı̆̆ında bu tarz hataların bir kısmının orada olmadığı, kitaplaşma sürecinde oluştuğu, bununla beraber bir kısmının ise tezde de yer aldı̆̆ı görülmektedir:

Tez s. 190-191 $\rightarrow$ a, aç-, ada, Adaş Kaya, adak, adaklıg, adaksız, adın, adınçıg, adıra, adırt, adırtla-, adırtlamak, adkan-. 


\section{$\mathrm{J}(\mathrm{O})$}

Tez s. 261-263 $\rightarrow$ sezin-, smarta, sola-, söz, sözlä-, sözlämäk, sözlämäklig, s1k-, sıĐar, sınça, sırıçga, siḍi, sim, sudur, sukançıg, sumlım, suv.

Ayrıca bu sıralama hataları madde esaslı değil de satır esaslı olduğu için bazı verilerde karşıllklara da yol açmaktadır. Örnek olarak s. 204'te al 'usul, yöntem' maddesi altında gösterilen bölä a.-layu ve çıngarıp $a_{\text {.- }} p$ verilerinin '-' işareti sebebiyle al ismi değil de bir fiil olduğu anlaşılmakta, ancak a.- kısaltması sebebiyle bu fiilin hangisi olduğu ancak metne gidilerek görülmektedir. $\mathrm{Bu}$ sebeple dizinin titizlikle yeniden ele alınması çalışmanın kullanımı için faydalı olacaktır.

Dizindeki bir başka durum ise / $\mathrm{j} /$ sesinin sırasıdır. Altun Yaruk örnekleminde ajun kelimesi için bu durum ele alınırsa, son yıllarda Türkiye'deki Eski Uygurca metin çalışmalarında bu sesin dizinde dört farklı tutuma göre yer aldığı görülür:

/j/ sesini [j] harfiyle göstermek ve alfabede [i] harfinden sonraya koymak: AY-III, UAY, AY-VII, AY-VIII, AY-IX

/j/ sesini [ [z] harfiyle göstermek ve alfabenin son sırasına koymak: AY-VI, AY-AB

/j/ sesini [ž] harfiyle göstermek ve alfabede [i] harfinden sonraya koymak: AY-IV

/j/ sesini [3] harfiyle göstermek ve alfabenin son sırasına koymak: AY-Ç

$\mathrm{Bu}$ çalışmasında, Uzunkaya'nın ikinci tutuma göre davrandığı anlaşılmaktadır.

Çince - Uygurca Dizin kısmında 328 Çince sözün Eski Uygurca karşılıkları gösterilmiş, Íkilemeler Dizini kısmında ise 58 ikilemeye yer verilmiştir.

Eski Uygurca sahasında eskiden yayınlanmış metinlerin, bilimsel gelişmelerin bu eserlere yansıtılmasıyla yeniden ele alınması önemlidir. Ülkemizde ve yurtdışında bu tür çalışmaların son yıllarda artması sevindiricidir. Uzunkaya'yı Türkische Turfan Texte-V metinlerini ilavelerle Türkiye Türkçesinde hazırlaması sebebiyle tebrik eder, çalışmalarının devamını dilerim.

\section{Kisaltmalar}

$\mathrm{AY}-\mathrm{AB}=$ Gulcalı 2013.

AY-Ç = Çă̆atay 1945.

AY-III = Ölmez 1991. 


\section{J(e)}

AY-IV = Tokyürek 2018.

AY-IX = Uçar 2013.

AY-VI = Ayazl1 2012.

AY-VII = Çetin 2012.

$\mathrm{AY}-\mathrm{VIII}=$ Çetin 2017.

Tez = Uzunkaya 2017 .

$\mathrm{UAY}=$ Kaya 1994.

\section{Kaynakça}

Çağatay, S. Ş. (1945). Altun Yaruk'tan İki Parça. I. Kü̈ü Tav'in canlları öldürdüğünden dolayı gördüğü ceza. II. Üç Prensle Pars hikâyesi (Prens Mahasatvi). Ankara Üniversitesi Dil ve Tarih-Coğrafya Fakültesi Yayınları.

Çetin, E. (2012). Altun Yaruk Yedinci Kitap. Berlin Bilimler Akademisindeki Metin Parçaları, Karşılaştırmalı Metin, Çeviri, Açıklamalar, Dizin. Karahan Kitabevi.

Çetin, E. (2017). Altun Yaruk Sekizinci Kitap, Berlin Bilimler Akademisindeki Metin Parçaları, Karşılaştırmalı Metin, Çeviri, Açıklamalar, Dizin. Karahan Kitabevi.

Gulcalı, Z. (2013). Eski Uygurca Altun Yaruk Sudur'dan 'Aç Bars' Hikâyesi. Türk Dil Kurumu Yayınları.

Kaya, C. (1994). Uygurca Altun Yaruk Giriş, Metin ve Dizin. Türk Dil Kurumu Yayınları.

Ölmez, M. (1991). Altun Yaruk III. Kitap (= 5. Bölüm) (Suvarnaprabhâsasûtra). Türk Dilleri Araştırmaları Dizisi.

Tokyürek, H. (2012). Altun Yaruk Sudur. VI. Kitap, Karşılaştırmalı Metin Yayını. Türk Dil Kurumu Yayınları.

Tokyürek, H. (2018). Altun Yaruk Sudur. IV. Tegzinç (Karşılaştırmalı Metin Yayını). Türk Dil Kurumu Yayınları.

Uçar, E. (2013). Uygurca Altun Yaruk Sudur IX. Tegzinç. Diplomatik Neşir Usûlüyle Yayını, Tercüme, Açıklamalar ve Dizin. Dinozor Kitabevi.

Uzunkaya, U. (2017). Son Dönem Budist Uygur Edebiyatından İki Örnek (Metin-ÇeviriAçıklamalar-Dizin). Yıldız Teknik Üniversitesi, Sosyal Bilimler Enstitüsü. (Yayımlanan Doktora Tezi)

Uzunkaya, U. (2020). Budist Eski Uygur Edebiyatından İki Metin. Kesit Yayınları. 